\title{
Quality Teaching of Mathematical Modelling: What Do We Know, What Can We Do?
}

\author{
Werner Blum
}

\section{Introduction}

The topic of this paper is mathematical modelling or-as it is often, more broadly, called-applications and modelling. This has been an important topic in mathematics education during the last few decades, beginning in particular with Henry Pollak's survey lecture (Pollak 1979) at ICME-3, Karlsruhe 1976 (my first ICME). By using the term "applications and modelling", both the products and the processes in the interplay between the real world and mathematics are addressed. In this paper, I will try to summarize some important aspects, in particular, concerning the teaching of applications and modelling. For obvious reasons, I have to restrict myself and hence omit some important aspects, such as gender issues or the question of how to embed applications and modelling in curricula and lessons. My paper is mainly a survey, only occasionally I can go into depth. I will concentrate on the secondary school level. I hope it will become clear that we have made considerable progress in the field during the last few decades, both theoretically and empirically, although still a lot remains to be done. For those who would like to find more on this topic I would refer to ICMI Study 14 on Modelling and Applications in Mathematics Education (Blum et al. 2007) where one can also find a short history of the field. Further, I would refer to the Proceedings of the ICTMA conference series (the International Conferences on the Teaching of Mathematical Modelling and Applications), held biennially since 1983. One can see how dynamically the filed develops by only looking at the number of papers in these books (see the last two Volumes: Kaiser et al. 2011, and Stillman et al. 2013).

In this paper, I will switch between theoretical aspects (Parts 2 and 4) and empirical aspects (Parts 3, 5-7). Part 8 is on teacher education, and I will start and close with concrete examples (Parts 1 and 9).

\footnotetext{
W. Blum ( $\square)$

University of Kassel (Germany), Institute of Mathematics, Kassel, Germany

e-mail: blum@mathematik.uni-kassel.de

(C) The Author(s) 2015 


\section{Two Introductory Real World Examples}

I work and live in Kassel, the city where, every five years, the "documentas" take place, the world's most important exhibitions for contemporary art (in 2012 with 850.000 visitors). Each documenta leaves some of its exhibits in the city. One of those is Claes Oldenburg's oversized pick-axe from documenta-7, 1982 (see Fig. 1).

The story that Oldenburg invented and Kassel people like to continue to tell is that Hercules, the landmark of Kassel (see Fig. 2), has thrown this pick-axe from his place, in the mountain park Wilhelmshöhe above Kassel, to the Fulda river. I will come back to this story in the final part of my paper.

Fig. 1 Oldenburg's pick-axe in Kassel

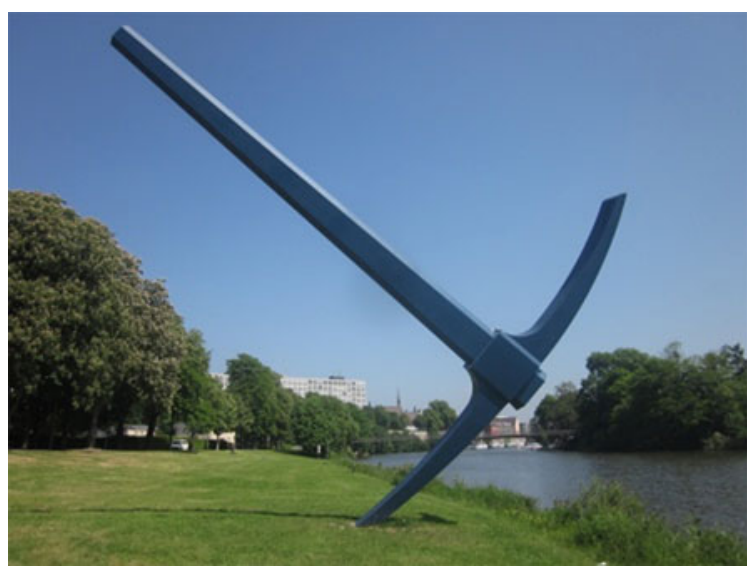

Fig. 2 The Kassel Hercules

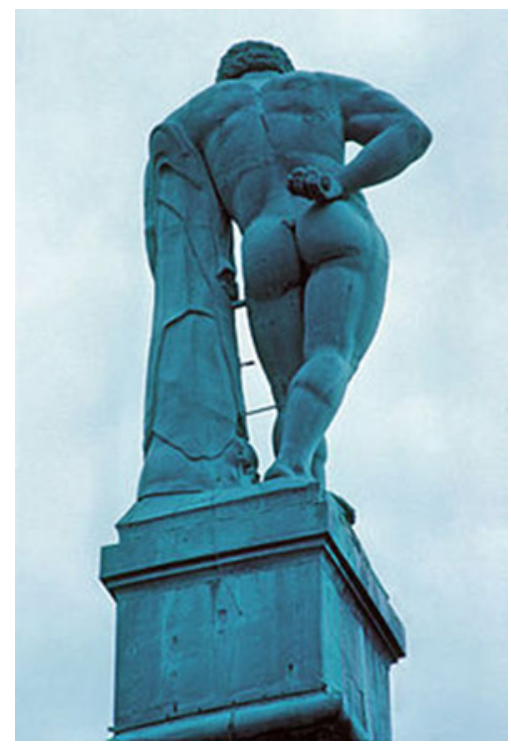


The first question is: How tall would a giant have to be for this pick-axe to fit to him? Would it fit to the Kassel Hercules himself?

Following Pollak's famous characterization of modelling "Here is a situationthink about it" (Pollak 1969), we begin with comparing the pick-axe and a normal person. Using proportionality, we find that this pick-axe is about $13 \mathrm{~m}$ long. A normal pick-axe measures about $1 \mathrm{~m}$. So, using again a proportional model, we find that a suitable giant would be about $25 \mathrm{~m}$ tall or, better perhaps, something between 20 and $30 \mathrm{~m}$. The Kassel Hercules measures only $9 \mathrm{~m}$, so he seems a bit too small for this pick-axe, unfortunately.

$$
\begin{aligned}
& x: 1.80 \approx 13: 1 \\
& x \approx 23.40
\end{aligned}
$$

A second example from documenta in Kassel: During documenta everything is more expensive in downtown Kassel. A Hercules T-shirt, for instance, as a Kassel souvenir, costs $15.99 €$ downtown, whereas in the shopping mall dez which is not far away, the same T-shirt costs only $12.99 €$. The second question is: Is it worthwhile to drive to dez in order to buy this T-shirt there?

We will solve this problem in several steps (the same steps that we have applied also in the pick-axe example without noticing it).

Step 1: We construct a mental model of the situation (Fig. 3).

Step 2: We simplify and structure this mental model by assuming that we go by car, that our car consumes $101 / 100 \mathrm{~km}$ in the city, that the gas costs $1.599 € / 1$ and that the distance we have to drive from downtown to the mall is $5 \mathrm{~km}$.

Fig. 3 Mental map of the situation

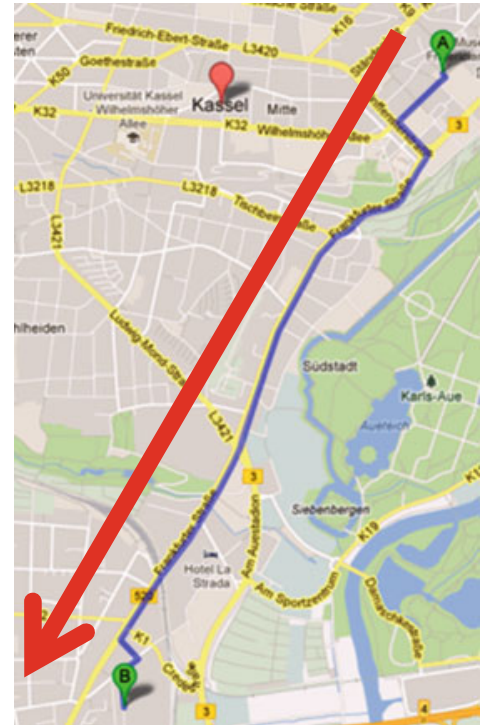


Step 3: We construct a suitable mathematical model by mathematizing these concepts and relations:

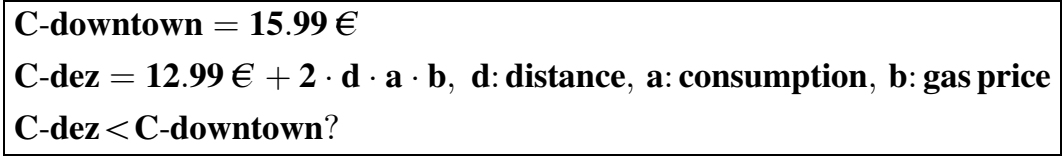

Step 4: We work mathematically by calculating $C-d e z \approx 12.99 €+1.60 €=14.59 €$ and by comparing: Yes, C-dez $<\mathrm{C}$-downtown!

Step 5: We interpret this mathematical result in the real world: It is indeed by $1.40 €$ cheaper to drive to the shopping mall!

Step 6: We validate our result: Does it really make sense to drive $10 \mathrm{~km}$ in order to save $1.40 €$ ? What about using this time instead to see more of Kassel's beauties? What about the risk of an accident or the air pollution caused by our trip? So perhaps we will refine our model and start again, or we will simply decide against that simple mathematical solution.

Step 7: In the end, we write down the whole solution.

This seven-step-process is one of the many schemas for the modelling process (Fig. 4, see Blum and Leiß 2007a).

Here are a few more such schemas (Fig. 5).

All these schemas have their specific strength and weaknesses, depending on the respective purposes. For cognitive analyses, this seven-step-model seems particularly helpful. It is a blend of models from applied mathematics (Pollak 1979; Burghes 1986), linguistics (Kintsch and Greeno 1985) and cognitive psychology (Staub and Reusser 1995).

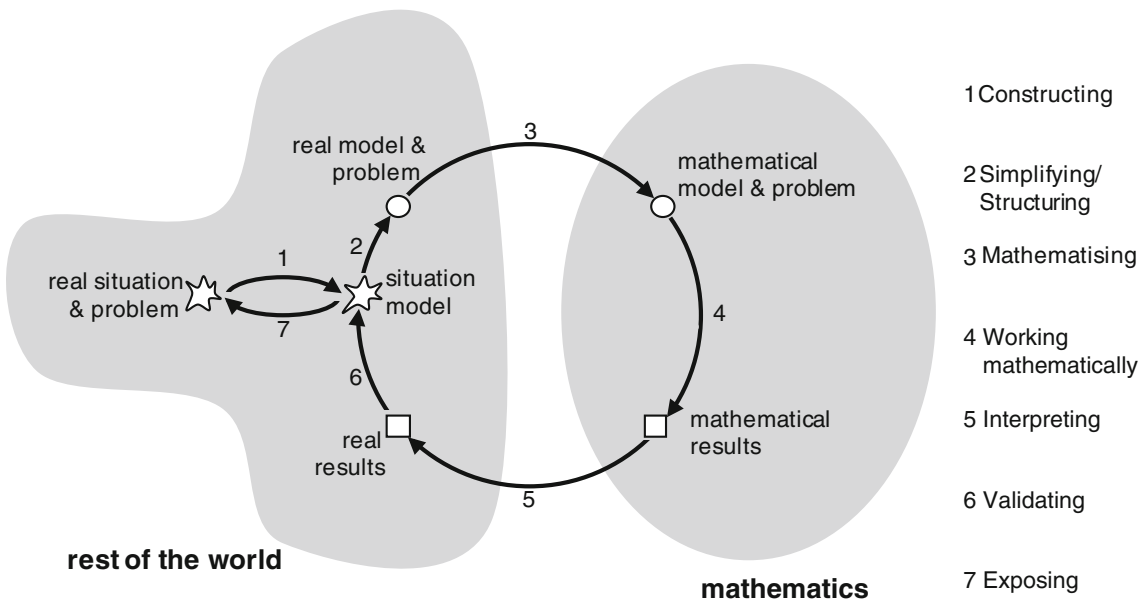

Fig. 4 Seven step modelling schema 

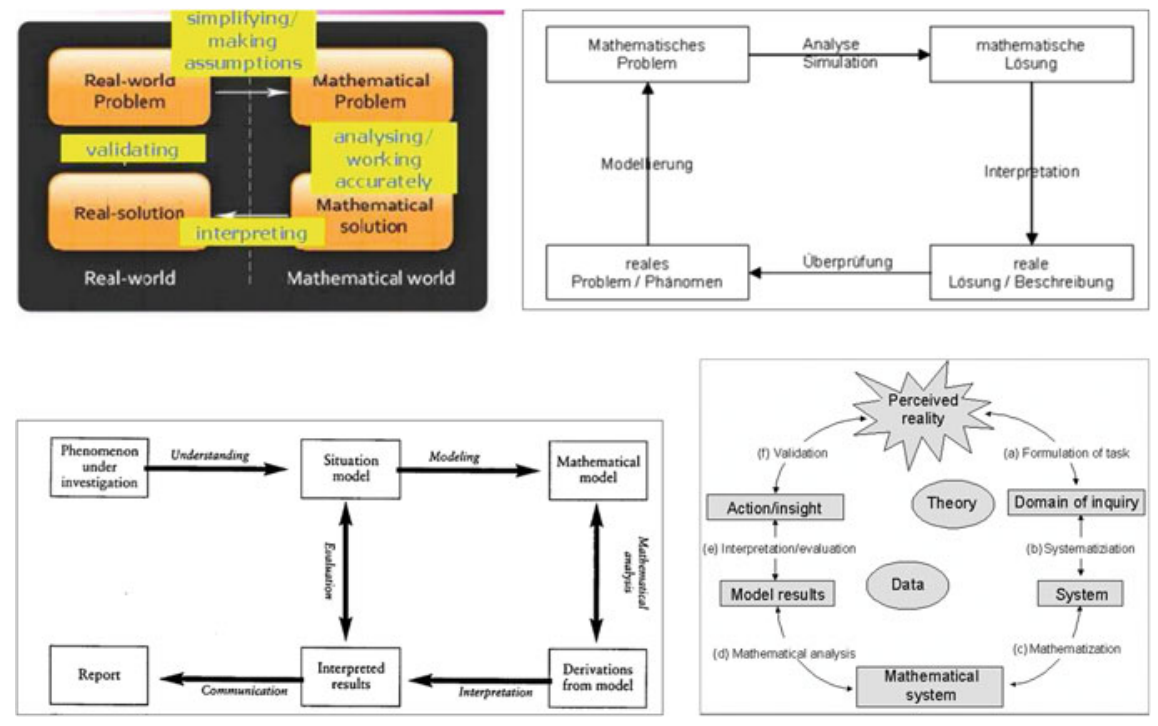

Fig. 5 Modelling schemas

\section{Mathematical Modelling Competency}

Here comes some theory. The topic of this paper is the teaching and learning of mathematics in the context of relations between mathematic and the extra-mathematical world. The latter is often called reality or the real world, or better, in the words of Pollak (1979), the "rest of the world", including nature, culture, society, or everyday life. The process of solving real world problems by means of mathematics can, from a cognitive point of view, be described by the schema from Fig. 4. If need be, one has to go round the loop several times. A key concept here is the concept of a model. A mathematical model is a deliberately simplified and formalized image of some part of the real world, formally speaking: a triple (D, M, f) consisting of a domain $\mathrm{D}$ of the real world, a subset $\mathrm{M}$ of the mathematical world and a mapping from D to $\mathrm{M}$ (Niss et al. 2007). Among the purposes of models are not only describing and explaining ("descriptive models") but also predicting and even creating parts of the real world ("normative models").

In the language of competencies according to Niss and colleagues (see Niss 2003), the ability to carry out those steps corresponds to certain competencies or sub-competencies such as understanding a given real world situation or interpreting mathematical results in relation to a situation (Blomhøj and Jensen 2007; Maaß 2006; Kaiser 2007; Turner et al. 2013). Cognitively speaking, an individual's competency is his/her ability to carry out certain actions in a well-aimed way. Modelling competency in a comprehensive sense means the ability to construct and to use or apply mathematical models by carrying out appropriate steps as well as to 
analyse or to compare given models (Blum et al. 2007). It is this comprehensive idea of modelling that will be used in the following.

The Niss competencies are also the conceptual basis for the PISA study and for the heart of PISA, mathematical literacy (see, e.g., OECD 2013, p. $23 \mathrm{ff}$ ). In large parts, PISA items require some modelling in a broad sense. An important source for the PISA philosophy was Hans Freudenthal's view of "mathematical concepts, structures and ideas as tools to organise the phenomena of the physical, social and mental world" (Freudenthal 1983). It is an open question whether this spirit of PISA will be preserved also in future PISA cycles.

\section{Students' Modelling Activities}

Mathematical modelling is a cognitively demanding activity since several competencies involved, also non-mathematical ones, extra-mathematical knowledge is required, mathematical knowledge and, in particular for translations, conceptual ideas (in German: "Grundvorstellungen") are necessary (e.g., in the examples in part 1 , ideas about proportional functions), and appropriate beliefs and attitude are required, especially for more complex modelling activities.

These cognitive demands are responsible for empirical difficulty. Modelling is indeed rather difficult for students (see, for instance, Houston and Neill 2003, or Frejd and Ärlebäck 2011). Figure 6 shows the PISA task "Rock Concert".

The correct solution is C. In the OECD, only $26 \%$ of all 15-year-olds have solved this task correctly, in Finland, one of the top performing countries, only $37 \%$, and in Korea, another top performing country, even only $21 \%$. The PISA Mathematics Expert Group has shown that the empirical difficulty of PISA

Fig. 6 PISA task "Rock Concert"

$$
\begin{aligned}
& \text { ROCK CONCERT } \\
& \text { For a rock concert a rectangular field of size } \\
& 100 \mathrm{~m} \text { by } 50 \mathrm{~m} \text { was reserved for the audience. } \\
& \text { The concert was completely sold out and the } \\
& \text { field was full with all the fans standing. } \\
& \text { Which one of the following is likely to be the } \\
& \text { best estimate of the total number of people } \\
& \text { attending the concert? } \\
& \text { A } 2000 \\
& \text { B } 5000 \\
& \text { C } 20000 \\
& \text { D } 50000 \\
& \text { E } 100000
\end{aligned}
$$


mathematics tasks can indeed be substantially explained by the competencies needed to solve these tasks (see Turner et al. 2013).

Several studies have shown that each step in the modelling process (see Fig. 4) is a potential cognitive barrier for students, a potential "blockage" or "red flag situation" (Goos 2002; Galbraith and Stillman 2006; Stillman 2011). "The weakest link in their modelling chain will set the limits on what they can do" (Treilibs et al. 1980).

Here are some remarks to step 1 "Understanding the situation and constructing a situation model". Many students get stuck already here. This is not only or even not primarily a cognitive deficiency. For, many students around the world have learned, as part of the hidden curriculum, that they can survive without the effort of careful reading and understanding given contextual tasks. Instead, they successfully follow a substitute strategy for word problems: "Ignore the context, just extract all data from the text and calculate something according to a familiar schema" (see, e.g., Nesher 1980; Baruk 1985; Schoenfeld 1991; Lave 1992; Reusser and Stebler 1997; Verschaffel et al. 2000; Xin et al. 2007; de Bock, Verschaffel et al. 2010). Schoenfeld and Verschaffel speak of the "suspension of sense-making" when playing the "word problem game". This strategy even becomes more popular with age, and in the school context it may indeed make a lot of sense to follow this strategy in order to pass tests and to survive. This is empirically well documented, in very many countries. Here is a well-known example (Verschaffel et al. 2000):

450 soldiers must be bussed to their training site. Each army bus can hold 36 soldiers. How many busses are needed?

Popular answers are "12 busses remainder 18" or " 12.5 busses". Another example of a calculation without imagining the situation clearly is:

An orchestra needs 40 min for Beethoven's 6th symphony. How long will it take for Beethoven's 9th symphony?

The popular answer is 60 min. In the PISA task "Rock Concert" (see Fig. 6), the by far most attractive distractor (49\%) was no. 2 , the one that follows exactly the substitute strategy: $50 \cdot 100=5,000$.

Step 2 "Simplifying and structuring" is a source of difficulties as well. In particular, learners are afraid of making assumptions by themselves.

Step 6 "Validating" is mostly not present at all in students' solutions. Here (Fig. 7) is a solution of the pick-axe task.

The answer $254.84 \mathrm{~m}$ for the giant's height is, first, ridiculously accurate (rounding off is a rare event in mathematics classrooms) and, second, obviously much too big. However, students normally do not validate their solutions, it seems to be part of the "contract didactique": Checking the correctness and suitability of a solution is exclusively the teacher' responsibility!

I would like to mention a few other important empirical results concerning students' dealing with modelling tasks. Several studies have shown (Matos and Carreira 1997; Leiß 2007; Borromeo Ferri 2011; Schukajlow 2011; Sol et al. 2011): If students are dealing with modelling tasks independently, the process is normally non-linear according to one of those ideal-typical loops but rather characterized by jumps forth and back, by omissions or mini-loops. Borromeo Ferri (2007) speaks of 
Fig. 7 A student solution of the pick-axe task

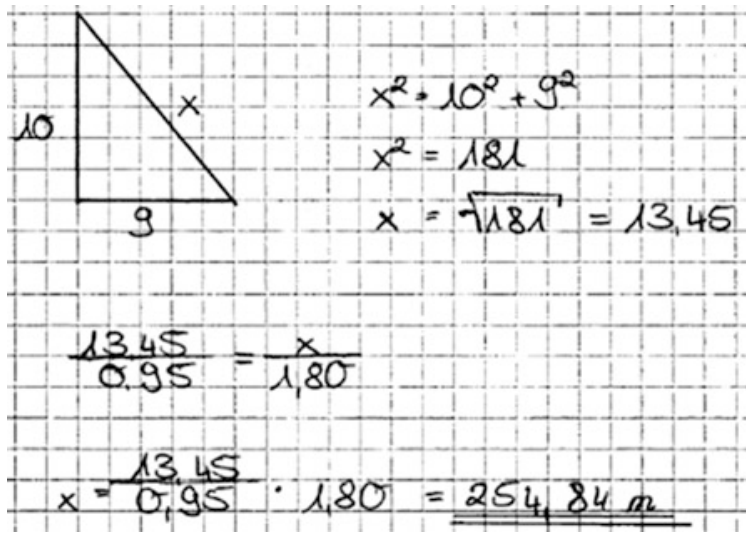

"individual modelling routes" which are determined by individual knowledge and preferences such as individual thinking styles.

Another well-documented observation is that students normally do not have strategies available for solving real world problems. More generally, students usually do not reflect upon their activities and, closely related to that, are not able to transfer their knowledge and skills from one context or task to a different context or task, even if there are structural similarities. For instance, in one of our projects, grade 9 students dealt in a lesson with the "Filling up" task (see Blum and Leiß 2006) which is quite analogous to the T-Shirt task from part 1 . The question is whether it is worthwhile for a certain Mrs. Stone to drive from her hometown Trier across the nearby border of Luxemburg, where the gas is cheaper, in order to fill up her car there. In the following test, the students had to solve very similar tasks, among others whether it is worthwhile to drive to a nearby strawberry field in order to pick the berries for a cake instead of buying them in a supermarket, or whether it is worthwhile to use cloth-diapers instead of disposable ones. For many students, these were totally new challenges, now about strawberries and diapers instead of cars. The PISA study also demonstrates every three years how difficult it is for 15year-olds to transfer their school knowledge to real world problem situations.

The phenomena just described are, as is well-known, special instances of situated cognition, or in the words of Jürgen Baumert: Every learning topic carries with it the "indices" referring to its learning context. This is particularly relevant for learning in the field of relations between the real world and mathematics (DeCorte et al. 1996; Niss 1999). Actually, when we report on empirical results about "modelling competency" we have to write this construct with several indices, especially referring to the mathematical topics and the extra-mathematical contexts involved. The question is even: Is there a "general modelling competency" at all? Much more research is necessary into how and how far the desired transfer can be achieved. I will come back to this aspect in parts 5 and 7 . 


\section{Aims and Perspectives of Modelling}

We come back to theoretical aspects of modelling. Modelling is a cognitively demanding activity, so why should learners have to deal with such activities? Why is it not sufficient to learn pure mathematics in order to achieve the aims of mathematics as a school subject? Mathematics is, as we know, a compulsory subject at school for the following reasons (see, e.g., Niss 1996): Mathematics as

- a powerful tool for better understanding and mastering present or future real world situations,

- a tool to develop general mathematical competencies,

- an important part of culture and society, and a world of its own.

The basis for that are general educational goals such as the ability to take part in social life as an independent and responsible citizen.

On this background, we can distinguish between four groups of justifications for the inclusion of applications and modelling in curricula and everyday teaching (see, e.g., Blum and Niss 1991; Blum 2011):

1. "pragmatic" justification: In order to understand and master real world situations, suitable applications and modelling examples have to be explicitly treated; we cannot expect any transfer from intra-mathematical activities.

2. "formative" justification: Competencies can be advanced also by engaging in modelling activities; in particular, modelling competency can only be advanced in this way, and argumentation competency can be advanced by "reality-related proofs" (Blum 1998).

3. "cultural" justification: Relations to the extra-mathematical world are indispensable for an adequate picture of mathematics as a science in a comprehensive sense.

4. "psychological" justification: Real world examples may contribute to raise students' interest in mathematics, to motivate or structure mathematical content, to better understand it and to retain it longer.

We can see a certain duality here (Niss et al. 2007): Whereas the first aspect deals with mathematics as an aid for the real world, the other three aspects deal with the opposite direction, the real world as an aid for mathematics, in a broad sense. Instead of "justifications for the inclusion of applications and modelling" we could also say "aims of the teaching of applications and modelling".

In order to advance those aims, suitable examples are needed. There is a broad spectrum of real world examples, from small dressed-up word problems to authentic modelling problems or projects that require days or weeks. The justifications or aims just mentioned require certain specific types of examples:

- "pragmatic": concrete authentic examples (from shopping, newspapers, taxes, traffic flow, wind park planning, air fare calculation, ...);

- "formative": cognitively rich examples, accompanied by meta-cognitive activities; 
- "cultural": either authentic examples that show students how strongly mathematics shapes the world (sometimes hidden and invisible, embedded in technology - the famous relevance paradox, see e.g. Niss 1999) or epistemologically rich examples that shed some light on mathematics as a science (including ethno-mathematical examples); in both cases, the role of mathematics and its relations to the real world must be made more conscious;

- "psychological": either interesting examples for motivation or illustration purposes, to make mathematics better marketable for students (these examples might quite well be dressed-up or whimsy problems, it is only a matter of honesty), or mathematically rich examples that serve the purpose to make certain mathematical topics better comprehensible.

So, examples are not good or bad per se, it depends on their purpose.

It was Gabriele Kaiser's idea, together with colleagues (see Kaiser et al. 2006), to distinguish between various perspectives of modelling. On the basis of what I have just presented, I have conceptualized the notion of "perspective" a bit more formally, as a pair (aim | suitable examples), with a slightly different terminology. So we can distinguish between six perspectives.

- (pragmatic | authentic) $\rightarrow$ “applied modelling” (Burghes, Haines, Kaiser, and others; particularly rooted in the Anglo-Saxon tradition)

- (formative | cognitively rich) $\rightarrow$ "educational modelling" (Burkhardt/Swan, Blomhøj, and others)

- (cultural with an emancipatory intention $\mid$ authentic) $\rightarrow$ "socio-critical modelling" (Keitel/Jablonka, Skovsmose, Julie, Barbosa, and others)

- (cultural concerning mathematics $\mid$ epistemologically rich) $\rightarrow$ "epistemological modelling" (d'Ambrosio, Garcia, Bosch, and others; more rooted in the Romanic tradition)

- (psychological with marketing intention $\mid$ motivating) $\rightarrow$ "pedagogical modelling" (by far the most important aspect in school)

- (psychological | mathematically rich) $\rightarrow$ "conceptual modelling" (Freudenthal, de Lange, Gravemeijer, and others)

For each perspective, there is a certain model of the modelling process that is best suitable for that purpose. For instance, for applied modelling, a four step model "Mathematising $\rightarrow$ Math. Working $\rightarrow$ Interpreting $\rightarrow$ Validating" seems most appropriate. There is no space here to elaborate more on this. In effect, it is more appropriate to conceptualise a "perspective" as a tripel (aim | examples | cycle).

All these perspectives also contribute to the question of sense-making. Here, I mean by the "sense" of an activity the subjective meaning of this activity to the individual whereby the individual can understand the purpose of this activity. Each perspective offers to learners a specific aspect of sense:

- "applied": sense through understanding and mastering real world situations

- "educational": sense through realizing own competency growth

- "socio-critical": sense through understanding the role of mathematics

- "epistemological": sense through comprehending mathematics as a science 
- "pedagogical": sense through enjoying doing mathematics

- "conceptual": sense through understanding mathematical concepts

It is important to offer various aspects of sense since learners will react differently, also according to their beliefs about and attitudes towards mathematics. The hope is that, by offering various aspects of sense, students' beliefs will become broader, and their attitudes will become more positive.

\section{Teaching Modelling}

Back from theory to practice. In the first few parts of this paper, the focus was on learning. It is clear that all aims and purposes can only be reached by high-quality teaching. Applications and modelling are important, and learning applications and modelling is demanding. This implies that there have to be particularly big efforts to make applications and modelling accessible for learners. In fact, there are such efforts in many countries around the world. However, in everyday mathematics teaching practice in most countries, there is still relatively few modelling. Applications in the classroom still occur mostly in the context of dressed-up word problems. We have been deploring this gap between the educational debate and classroom practice for decades. Why do we still have this gap? The main reason is that teaching applications and modelling is demanding, too (Freudenthal 1973; Pollak 1979; DeLange 1987; Burkhardt 2004; Ikeda 2007). Also the teachers have to have various competencies available, mathematical and extra-mathematical knowledge, ideas for tasks and for teaching as well as appropriate beliefs. Instruction becomes more open and assessment becomes more complex. This is the main barrier for applications and modelling.

What can we do to improve the situation? What do we know empirically about effective teaching of applications and modelling according to those various aims and purposes? Generally speaking, the well-known findings on quality mathematics teaching of mathematics hold, of course, also for teaching mathematics in the context of relations to the real world. This seems self-evident but is ignored in classrooms around the world every day a million times.

In the following, I will present ten-in my view-important aspects for a teaching methodology for applications and modelling, based on empirical findings.

1. A necessary condition is an effective and learner-oriented classroom management (see, e.g., Baumert et al. 2004; Hattie 2009; Timperley 2011; Kunter and Voss 2013): using time effectively, separating learning and assessment recognisably, using students' mistakes constructively as learning opportunities (motto: every wrong answer is the right answer to a different question), or varying methods and media flexibly. For modelling, group work is particularly suitable (Ikeda and Stephens 2001). The group is not only a social but also a cognitive environment (co-constructive group work; see Reusser 2001). 
2. Just as necessary is to activate learners cognitively, to stimulate students' own activities. "Modelling is not a spectator sport" (Schoenfeld, personal communication), one can expect learning effects at most if students engage actively in modelling. This is not a matter of surface structures such as whole-class teaching versus group work versus individualized teaching, which may be dependent on cultural backgrounds. What only counts is that learners are cognitively active (Schoenfeld 1992). We have to distinguish carefully here between students working independently with teacher support, on the one hand, and, on the other hand, students working on their own, alone. Crucial for teaching is a permanent balance between students 'independence and teacher's guidance, according to Aebli's famous "Principle of minimal support" (Aebli 1985). I will come back to this aspect in part 6 of this paper.

3. Learners have to be activated not only cognitively but also meta-cognitively. All activities ought to be accompanied by reflections and ought to be reflected in retrospective, with the aim to advance appropriate learning strategies. Again this is not a matter of lesson surface structures. I will elaborate more on this aspect in part 7 of this paper.

4. There has to be a broad variety of suitable examples as the substance of mathematics lessons since we cannot expect any mystical transfer from one example or context to another. In particular, there has to be a well-aimed variation of real world contexts as well as of mathematical contexts and topics. As I have said in part 4, different kinds of examples may serve different purposes and authenticity is not always required. However, if contexts are made more authentic, the "suspension of sense-making" (see part 3) can be reduced substantially (Palm 2007; Verschaffel et al. 2010). For instance, if the "Army bus" task (see part 3 ) is embedded in a credible context where students have to write an order form for a bus company, the number of reasonable solutions increases substantially.

There are a lot of rich teaching/learning environments available for all aims of application and modelling, among many others the following:

- A wealth of materials from the Shell Centre in Nottingham, the UCSMP project, Roskilde University, the Freudenthal institute (RME) and much more (see Blum et al. 2007, part 6).

- Dick Lesh's Model Eliciting Activities (Lesh and Doerr 2003); they are primarily meant as a research tool, but they can be used equally well for teaching purposes, together with his Model Exploration Activities and Model Adaptation Activities.

- "Real objects, contexts and actions" and "local applications" (Alsina 2007); other outdoor activities in the same spirit are "Maths trails" (see, e.g., Shoaf et al. 2004).

- Materials from the modelling weeks in various cities, in Germany, Singapore or Queensland. 
5. Teachers ought to encourage individual solutions of modelling tasks. In everyday teaching practice, however, teachers tend to favour strongly their own solution, without even noticing it (Leikin and Levav-Waynberg 2007; Borromeo Ferri and Blum 2009), also because of a limited knowledge of the "task space". There are several reasons for encouraging multiple solutions (Schoenfeld 1988; Hiebert and Carpenter 1992; Krainer 1993; Neubrand 2006; Rittle-Johnson and Star 2009; Tsamir et al. 2010): These comply with students' individual preferences, support internal differentiation in the classroom, reflect the genuine spirit of mathematics, and enable comparisons between and reflections on different solutions on a meta-level. In the current project MultiMa (Schukajlow and Krug 2013), two independency-oriented teaching units with modelling tasks are compared where in one unit students are explicitly required to produce multiple solutions. It turned out that those students who developed several solutions had higher learning gains.

6. Competencies such as modelling evolve in long-term learning processes, beginning already in primary school with "implicit models" (Greer and Verschaffel 2007; Borromeo Ferri and Lesh 2013) and continuing forever. Necessary and not at all out-of-date are permanent integrated repeating and intelligent practising. It is also important to have a permanent balance between focussing on sub-competencies of modelling and focussing on modelling competency as a whole. It is an open research question what such a balance would look like. What would be needed is a competency development model for modelling, theoretically sound and empirically well-founded, or several such models. This is a big deficit in research.

An interesting approach to describe competency development comes from the Danish KOM project (Blomhøj and Jensen 2007; Niss and Højgaard Jensen 2011). The authors distinguish between three dimensions in an individual's possession of a given mathematical competency: the "degree of coverage" of aspects of this competency, the "radius of action" that indicates the spectrum of contexts and situations, and the "technical level" that indicates the conceptual and technical level of the involved mathematical entities.

7. Not only teaching but also assessment has to reflect the aims of applications and modelling appropriately. Quality criteria such as variation of methods are relevant here, too (Haines and Crouch 2001; Izard et al. 2003; Houston 2007; Antonius et al. 2007; Vos 2007). One method is, of course, to work with tests. As we know, tests have several functions, among others to set norms and to illustrate the aspired aims ("What You Test Is What You Get"), but also and particularly to diagnose students' strengths and weaknesses in order to know better how to help.

An interesting research question is whether and how it is possible to assess modelling sub-competencies and general modelling competency separately. Zöttl et al. (2011) have found that the following model describes their data best (Fig. 8): Some items measure certain sub-competencies and all items measure a general competency. 
Fig. 8 Model for modelling sub-competencies

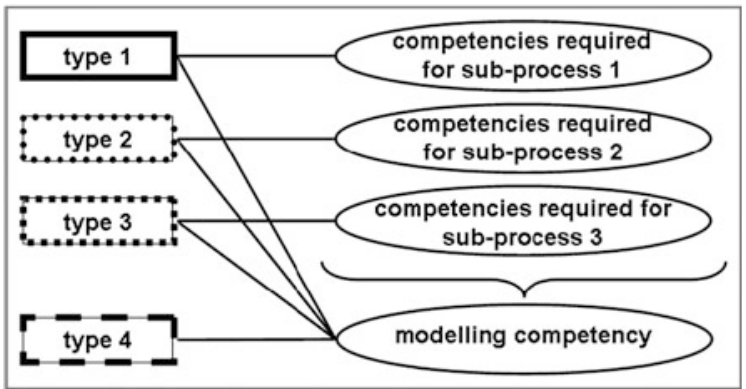

8. It is important to care for a parallel development of competencies and appropriate beliefs and attitudes. Taking into account the remarkable stability of beliefs and attitudes, this also requires long-term learning processes.

9. There are a lot of case studies that show that digital technologies can be used as powerful tools for modelling activities, not only in the intra-mathematical phases (see, e.g., Borba and Villarreal 2005; Henn 2007; Geiger 2011; Greefrath et al. 2011). Computers can be used for experiments, investigations, simulations, visualisations or calculations. Greefrath suggests to extend the modelling cycle by adding a third world: the technological world (Fig. 9). What we need here are much more controlled studies into the effects of digital technologies on modelling competency development.

10. The best message comes last. Several case studies have shown that mathematical modelling can in fact be learned by secondary school students supposed there is quality teaching (a.o. Kaiser-Meßmer 1987; Galbraith and Clatworthy 1990; Abrantes 1993; Maaß 2007; Biccard and Wessels 2011; Blum and Leiß 2007b; Schukajlow et al. 2012). Some studies have shown that also students' beliefs about mathematics can be broadened by appropriate quality teaching.

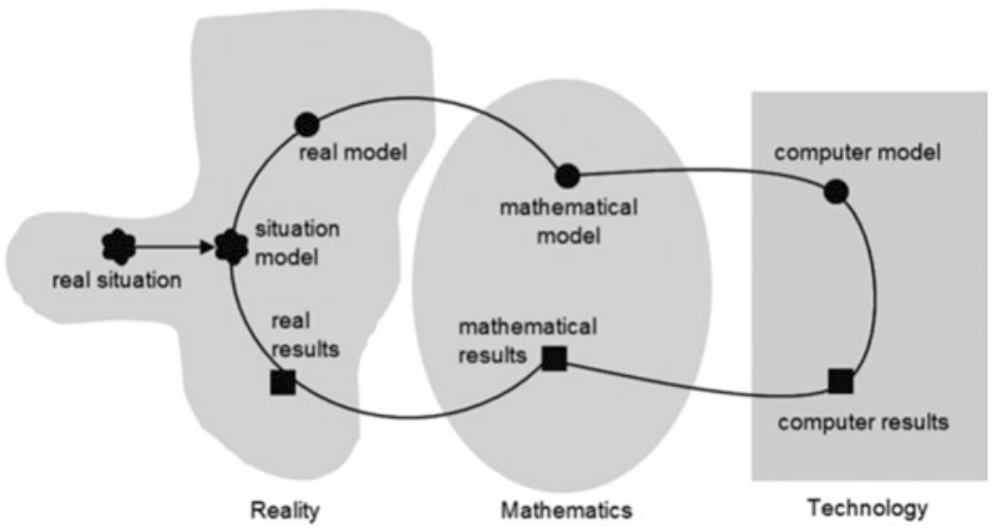

Fig. 9 The extended modelling cycle 
However, much more research is needed, especially small-scale studies using a mixture of qualitative and quantitative methods.

In closing part 5, I would like to emphasise that all these efforts will not be sufficient to assign applications and modelling its proper place in curricula and classrooms and to ensure effective and sustainable learning. The implementation of applications and modelling has to take place systemically, with all system components collaborating closely: curricula, standards, instruction, assessment and evaluation, and teacher education. I cannot elaborate more on this aspect.

\section{Teacher Support for Modelling Activities}

I would like to go more deeply into the second aspect mentioned in part 5: How can the balance between students' independent work and teacher's guidance be put into practice, what does "minimal support" look like? The key concept is adaptive teacher invention (see Leiß 2010, for an overview). Such an intervention allows students to continue their work without losing their independence-in the Vygotski terminology: an intervention in the Zone of Proximal Development. Whether an intervention was adaptive or not can, on principle, be only judged afterwards: Is the cognitive barrier really overcome, has the "red flag" vanished? Adaptive interventions can be regarded as a special case of scaffolding (Smit et al. 2013). A necessary basis for such a temporary support is a good diagnosis.

In everyday classrooms, teachers tend to strong, content-related interventions, sometimes in order to prevent mistakes or blockages before they occur. According to several studies (see, e.g., Leiß 2007), there are only very few strategic interventions, and most interventions seem to be not adaptive. However, especially strategic interventions have the potential of being adaptive (for an impressive example of a successful strategic intervention see Blum and Borromeo Ferri 2009). Here are some examples of strategic interventions:

Read the text carefully! Imagine the situation clearly! Make a sketch! What do you aim at? What is missing? Which data do you need? How far have you got? Does this result make sense for the real situation?

In the DISUM project (see Blum and Leiß 2007b), a ten lesson teaching unit on modelling in 18 grade 9 classes proved to produce significantly higher learning gains in modelling competency in a teaching design oriented towards students' independence with adaptive teacher interventions compared to a design with directive teaching; see Schukajlow et al. (2012) for more details. 


\section{Strategies for Learning Modelling}

All teacher interventions and support as just discussed will have no long-term effects if they are only applied situationally, transfer cannot be expected. Only accompanying meta-cognitive activities may promise sustainable effects. Students have to be enabled to see the general feature in the concrete step, in the concrete cognitive barrier: How can I help myself in such a difficulty? How can I solve such kind of tasks by myself? For, in assessment situations or in real life contexts, there is no teacher support available.

A promising approach is to teach learning strategies, cognitive strategies as well as meta-cognitive strategies such as planning, controlling or regulating. There are a lot of empirical results concerning the effects of using strategies, mostly encouraging, some also disappointing (Tanner and Jones 1993; Schoenfeld 1992, 1994; Matos and Carreira 1997; Stillman and Galbraith 1998; Kramarski et al. 2002; Burkhardt and Pollak 2006; Desoete and Veenman 2006; Stillman 2011; for an overview see Greer and Verschaffel 2007). One of the problems in these empirical studies is: how to measure strategy knowledge, on the one hand, and strategy use, on the other hand, and another problem is how to reliably link students' activities to their strategies.

In particular for novices in modelling there are two strategic instruments that I would like to mention since they turned out to be successful: First, the heuristic worked examples in the KOMMA project, with a three step schema (see Zöttl et al. 2011). Second, the DISUM four step schema ("Understanding task/ Searching mathematics/ Using mathematics/ Explaining result"; see Blum 2011, for more details). This is not meant as a schema that students must follow but as a guiding line, a meta-cognitive aid, particularly in case of difficulties. The problem for students with such strategic devices is: What do these hints mean concretely (for instance in step 2 "Make assumptions": which, how, how many?)? Much more research is needed into the design and use of strategic instruments for modelling.

\section{Teacher Competencies for Modelling}

Several empirical studies tell us (recently the comparative study TEDS-M, see Schmidt et al. 2007; Blömeke et al. 2010): The teacher matters most! For quality teaching of applications and modelling, the teacher needs a lot of different competencies. As a theoretical foundation, I would like to use the competence model from the COACTIV project (see Baumert and Kunter 2013). Here, as part of the professional knowledge, five categories are distinguished, especially content knowledge (CK), pedagogical content knowledge (PCK), and pedagogical/psychological knowledge (PK), along the distinction made by Shulman and others. Based on the fundamental assumption about the impact of teaching on learning 
teacher competencies $\rightarrow$ quality teaching $\rightarrow$ student learning,

the COACTIV project has shown, for a representative sample of German secondary mathematics teachers, that subject-related teacher competencies have a strong influence on students' performance (see Baumert et al. 2010). Among the mediators that significantly influence students' performance are classroom management and the cognitive level of tasks set for written class tests. And the TEDS-M study has shown that competencies of beginning teachers vary a lot across different countries, dependent on their learning opportunities. Therefore, teacher education is crucial.

What PCK is needed especially for teaching applications and modelling (see Ball et al. 2005, in general and, in particular for modelling, Doerr 2007; Lingefjärd 2013; Kaiser et al. 2010). Borromeo Ferri and Blum (2010) distinguish, in their model, between four dimensions of teachers' PCK for modelling: (1) a theoretical dimension (incl. modelling cycles or aims and perspectives of modelling as background knowledge), (2) a task dimension (incl. multiple solutions or cognitive analyses of modelling tasks), (3) an instructional dimension (incl. interventions, support and feedback), and (4) a diagnostic dimension (incl. recognising students' difficulties and mistakes). Also for teachers' learning, no transfer can be expected. Hence, all these elements have to be included as compulsory components in teacher education and professional development. Obviously, in most places where maths teachers are trained, this is not (yet) the case, that means the naïve faith in some mystic transfer is strong here, too. Another myth is that teachers will gain their necessary professional knowledge just by teaching practice. However, in the COACTIV project, there was no correlation between experience and professional knowledge (see Kunter et al. 2013).

One way of providing future teachers with the necessary professional knowledge is to offer specific modelling seminars already at the university, with compulsory own teaching experiences (Borromeo Ferri and Blum 2010). Also the Model Eliciting Activities mentioned in part 5 (see Doerr and Lesh 2011) are very efficient learning environments both for future and for practicing teachers. Nevertheless, a lot has still to be done in research as well, in particular: How will the various teacher competencies play out in teaching practice and how will they influence student learning about applications and modelling?

\section{A Final Real World Example}

I would like to come back to the example in part 1, Oldenburg's oversized pick-axe in Kassel. The story that the Kassel Hercules has thrown this pick-axe to the Fulda river is very nice, but we may ask: Is it conceivable? 


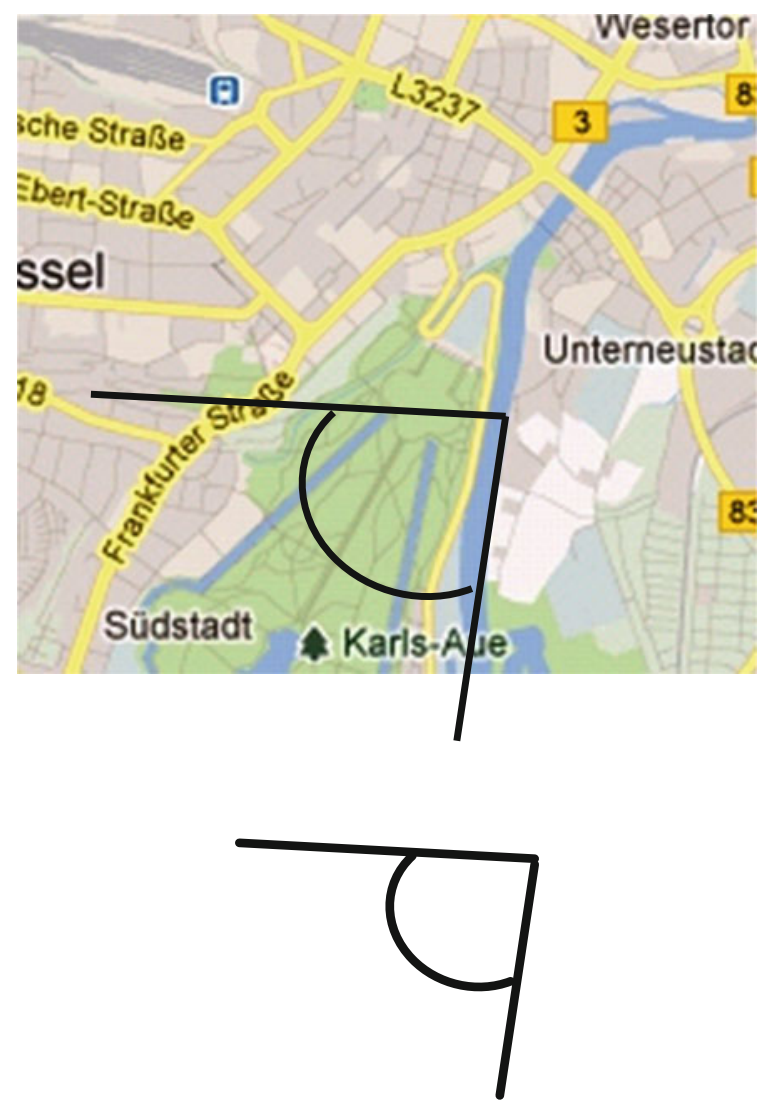

Fig. 10 The angle between axe and river

The first question is: Is the axis correct from the pick-axe to the Hercules? Hercules cannot be seen from the Fulda bank, but we can just measure the angle between the pick-axe and the Fulda River in reality and at the same time the angle between the line Hercules-axe and the river on the map (Fig. 10).

In both cases we find approximately $85^{\circ}$. Since angles are preserved under similarity transformations, this shows that the axis is correct indeed.

The second question is: Can Hercules really throw that far? This depends on a more basic question: Is Hercules able to hold this pick-axe at all? See part 1: Oldenburg's pick-axe is 13 times as long as a normal axe. So, using a cubic model, it weighs more than 2,000 times a normal axe, thus approximately 5 tons. Kassel's Hercules measures 9 m, 5 times a normal man's height, and Hercules is, as one knows from history, much stronger than normal people. The world record in weight-lifting is $1 / 4$ ton. Now we can apply two different models. If we assume that the power for weight-lifting only grows proportionally with height, Hercules will be able to hold at most 1.5 tons but not 5 tons, unfortunately. However, if we assume 
quadratic growth with height, Hercules will be able to hold even 6 tons. I would like to leave this question open: Which model is more appropriate? Personally, I prefer the quadratic model in order not to run down such a nice story about a hero and his pick-axe.

Open Access This chapter is distributed under the terms of the Creative Commons Attribution Noncommercial License, which permits any noncommercial use, distribution, and reproduction in any medium, provided the original author(s) and source are credited.

\section{References}

Abrantes, P. (1993). Project work in school mathematics. In: De Lange, J. et al. (Eds), Innovation in Maths Education by Modelling and Applications. Chichester: Horwood, 355-364.

Aebli, H. (1985). Zwölf Grundformen des Lehrens. Stuttgart: Klett-Cotta.

Alsina, C. (2007). Less chalk, less words, less symbols ... More objects, more context, more actions. In: Blum, W. et al. (Eds), Modelling and Applications in Mathematics Education. New York: Springer, 35-44.

Antonius, S. et al. (2007). Classroom activities and the teacher. In: Blum, W. et al. (Eds), Modelling and Applications in Mathematics Education. New York: Springer, 295-308.

Ball, D.L., Hill, H.C. \& Bass, H. (2005). Knowing mathematics for teaching. In: American Educator, 29 (3), 14-46.

Baruk, S. (1985). L'age du capitaine. De l'erreur en mathematiques. Paris: Seuil.

Baumert, J., Kunter, M. \& Blum, W. et al. (2004). Mathematikunterricht aus Sicht der PISASchülerinnen und -Schüler und ihrer Lehrkräfte. In: Prenzel, M. et al. (Eds), PISA 2003. Der Bildungsstand der Jugendlichen in Deutschland - Ergebnisse des zweiten internationalen Vergleichs. Waxmann, Münster, 314-354.

Baumert, J. \& Kunter, M. (2013). The COACTIV Model of Teachers' Professional Competence. In: Kunter, M., Baumert, J., Blum, W. et al. (Eds), Cognitive Activation in the Mathematics Classroom and Professional Competence of Teachers - Results from the COACTIV Project. New York: Springer, 25-48.

Baumert, J., Kunter, M., Blum, W. et al. (2010): Teachers' Mathematical Knowledge, Cognitive Activation in the Classroom, and Student Progress. In: American Educational Research Journal 47(1), 133-180.

Biccard, P. \& Wessels, D.C.J. (2011). Documenting the Development of Modelling Competencies of Grade 7 Students. In: Kaiser, G. et al. (Eds). Trends in Teaching and Learning of Mathematical Modelling (ICTMA 14). Dordrecht: Springer, 375-383.

Blömeke, S., Kaiser, G. \& Lehmann, R. (Eds, 2010). TEDS-M 2008: Professionelle Kompetenz und Lerngelegenheiten angehender Mathematiklehrkräfte für die Sekundarstufe I im internationalen Vergleich. Münster: Waxmann.

Blomhøj, M. \& Jensen, T.H. (2007). What's all the fuss about competencies? In: Blum, W. et al. (Eds), Modelling and Applications in Mathematics Education. New York: Springer, 45-56.

Blum, W. (1998). On the role of "Grundvorstellungen" for reality-related proofs - examples and reflections. In: Galbraith, P. et al. (Eds), Mathematical Modelling - Teaching and Assessment in a Technology-Rich World. Chichester: Horwood, 63-74.

Blum, W. (2011). Can Modelling Be Taught and Learnt? Some Answers from Empirical Research. In: Kaiser, G. et al. (Eds), Trends in Teaching and Learning of Mathematical Modelling (ICTMA 14). Dordrecht: Springer, 15-30.

Blum, W. \& Borromeo Ferri, R. (2009). Mathematical Modelling: Can it Be Taught and Learnt? In: Journal of Mathematical Modelling and Application 1(1), 45-58. 
Blum, W. \& Leiß, D. (2006). "Filling up" - The problem of independence-preserving teacher interventions in lessons with demanding modelling tasks. In: Bosch, M. (Ed.), CERME-4 Proceedings of the Fourth Conference of the European Society for Research in Mathematics Education. Guixol.

Blum, W. \& Leiß, D. (2007a). How do students' and teachers deal with modelling problems? In: Haines, C. et al. (Eds), Mathematical Modelling: Education, Engineering and Economics. Chichester: Horwood, 222-231.

Blum, W. \& Leiß, D. (2007b). Investigating Quality Mathematics Teaching - the DISUM Project. In: Bergsten, C. \& Grevholm, B. (Eds), Developing and Researching Quality in Mathematics Teaching and Learning, Proceedings of MADIF 5. Linköping: SMDF, 3-16.

Blum, W. \& Niss, M. (1991). Applied mathematical problem solving, modelling, applications, and links to other subjects - state, trends and issues in mathematics instruction. In: Educational Studies in Mathematics 22(1), 37-68.

Blum, W., Galbraith, P., Henn, H.-W. \& Niss, M. (Eds, 2007). Modelling and Applications in Mathematics Education. New York: Springer.

Borba, M.C. \& Villarreal, M.E. (2005). Humans-with-Media and the Reorganization of Mathematical Thinking - Informations and Communication Technologies, Modeling, Experimentation and Visualization. New York: Springer.

Borromeo Ferri, R. (2007). Modelling problems from a cognitive perspective. In: Haines, C. et al. (Eds), Mathematical Modelling: Education, Engineering and Economics. Chichester: Horwood, 260-270.

Borromeo Ferri, R. (2011). Wege zur Innenwelt des mathematischen Modellierens: Kognitive Analysen zu Modellierungsprozessen im Mathematikunterricht. Wiesbaden: Vieweg+Teubner.

Borromeo Ferri, R. \& Blum, W. (2009). Insight into Teachers' Unconscious Behaviour in Modeling Contexts. In: Lesh, R. et al. (Eds), Modeling Students' Mathematical Modeling Competencies. New York: Springer, 423-432.

Borromeo Ferri, R. \& Blum, W. (2010). Mathematical Modelling in Teacher Education Experiences from a Modelling Seminar. In: Durand-Guerrier, V., Soury-Lavergne, S. \& Arzarello, F. (Eds), CERME-6 - Proceedings of the Sixth Congress of the European Society for Research in Mathematics Education. INRP, Lyon 2010, 2046-2055.

Borromeo Ferri, R. \& Lesh, R. (2013). Should Interpretation Systems be Considered to be Models if they only Function Implicitly? In: Stillman, G. et al. (Eds). Teaching Mathematical Modelling: Connecting to Teaching and Research Practice - the Impact of Globalisation. New York: Springer.

Burghes, D. (1986). Mathematical modelling - are we heading in the right direction? In: J. Berry et al. (Eds), Mathematical Modelling Methodology, Models and Micros. Chichester: Horwood, 11-23.

Burkhardt, H. (2004). Establishing modelling in the curriculum: barriers and levers. In: Henn, H. W. \& Blum, W. (Eds), ICMI Study 14: Applications and Modelling in Mathematics Education Pre-Conference Volume. University of Dortmund, 53-58.

Burkhardt, H. \& Pollak, H.O. (2006). Modelling in mathematics classrooms: reflections on past developments and the future. In: Zentralblatt für Didaktik der Mathematik 38(2), 178-195.

DeCorte, E., Greer, B. \& Verschaffel, L. (1996). Mathematics teaching and learning. In: Berliner, D.C. \& Calfee, R.C. (Eds.), Handbook of Educational Psychology. New York: Macmillan, 491-549.

DeLange, J. (1987). Mathematics, Insight and Meaning. Utrecht: CD-Press.

Desoete, A. \& Veenman, M.V.J. (2006). Metacognition in mathematics education. Hauppauge: Nova Science Publishers.

Doerr, H. (2007). What knowledge do teachers need for teaching mathematics through applications and modelling? In: Blum, W. et al. (Eds), Modelling and Applications in Mathematics Education. New York: Springer, 69-78.

Doerr, H. \& Lesh, R. (2011). Models and Modelling Perspectives on Teaching and Learning Mathematics in the Twenty-First Century. In: Kaiser, G. et al. (Eds). Trends in Teaching and Learning of Mathematical Modelling (ICTMA 14). Dordrecht: Springer, 247-268. 
Frejd, P. \& Ärlebäck, J. (2011). First Results from a Study Investigating Swedish Upper Secondary Students' Mathematical Modelling Competencies. In: Kaiser, G. et al. (Eds). Trends in Teaching and Learning of Mathematical Modelling (ICTMA 14). Dordrecht: Springer, 407416.

Freudenthal, H. (1973). Mathematics as an Educational Task. Dordrecht: Reidel.

Freudenthal, H. (1983). Didactical Phenomenology of Mathematical Structures. Dordrecht: Reidel.

Galbraith, P. \& Clathworthy, N. (1990). Beyond standard models - Meeting the challenge of modelling. In: Educational Studies in Mathematics 21(2), 137-163.

Galbraith, P. \& Stillman, G. (2006). A framework for identifying student blockages during transitions in the modelling process. In: Zentralblatt für Didaktik der Mathematik 38(2), 143162.

Geiger, V. (2011). Factors Affecting Teachers' Adoption of Innovative Practices with Technology and Mathematical Modelling. In: Kaiser, G. et al. (Eds, 2011), Trends in Teaching and Learning of Mathematical Modelling (ICTMA 14). Dordrecht: Springer, 305-314.

Goos, M. (2002). Understanding metacognitive failure. In: Journal of Mathematical Behavior 21 (3), 283-302.

Greefrath, G., Siller, H.-S. \& Weitendorf, J. (2011). Modelling Considering the Influence of Technology. In: Kaiser, G. et al. (Eds, 2011), Trends in Teaching and Learning of Mathematical Modelling (ICTMA 14). Dordrecht: Springer, 315-329.

Greer, B. \& Verschaffel, L. (2007). Modelling competencies - overview. In: Blum, W. et al. (Eds). Modelling and Applications in Mathematics Education. New York: Springer, 219-224.

Haines, C. \& Crouch, R. (2001). Recognizing constructs within mathematical modelling. In: Teaching Mathematics and its Applications 20(3), 129-138.

Hattie, J.A.C. (2009): Visible Learning. A synthesis of over 800 meta-analyses relating to achievement. London \& New York: Routledge.

Henn, H.-W. (2007). Modelling pedagogy - Overview. In: Blum, W. et al. (Eds), Modelling and Applications in Mathematics Education. New York: Springer, 321-324.

Hiebert, J. \& Carpenter, T.P. (1992). Learning and teaching with understanding. In: D.A. Grouws (Ed.), Handbook of research on mathematics teaching and learning. New York: Macmillan, 65-97.

Houston, K. (2007). Assessing the "phases" of mathematical modelling. In: Blum, W. et al. (Eds), Modelling and Applications in Mathematics Education. New York: Springer, 249-256.

Houston, K., \& Neill, N. (2003). Assessing modelling skills. In: Lamon, S.J., Parker, W.A. \& Houston, S.K. (Eds), Mathematical modelling: A way of life - ICTMA 11. Chichester: Horwood, 155-164.

Ikeda, T. (2007). Possibilities for, and obstacles to teaching applications and modelling in the lower secondary levels. In: Blum, W. et al. (Eds), Modelling and Applications in Mathematics Education. New York: Springer, 457-462.

Ikeda, T. \& Stephens, M. (2001). The effects of students' discussion in mathematical modelling. In: Matos, J.F., Blum, W., Houston, S.K. \& Carreira, S.P. (Eds.), Modelling and Mathematics Education: Applications in Science and Technology. Chichester: Horwood, 381-390.

Izard, J., Haines, C.R., Crouch, R.M., Houston, S.K. \& Neill, N. (2003). Assessing the impact of the teaching of modelling. In: Lamon, S., Parker, W. \& Houston, S.K. (Eds), Mathematical Modelling: A Way of Life. Chichester: Horwood, 165-178.

Kaiser-Meßmer, G. (1987). Application-oriented mathematics teaching. In: Blum, W. et al. (Eds), Applications and Modelling in Learning and Teaching Mathematics. Chichester: Horwood, 66-72.

Kaiser, G. (2007). Modelling and modelling competencies in school. In: Haines, C. et al. (Eds), Mathematical Modelling: Education, Engineering and Economics. Chichester: Horwood, 110-119.

Kaiser, G., Blum, W., Borromeo Ferri, R. \& Stillman, G. (Eds, 2011). Trends in Teaching and Learning of Mathematical Modelling (ICTMA 14). Dordrecht: Springer. 
Kaiser, G., Blomhøj, M. \& Sriraman, B. (Eds, 2006). Mathematical modelling and applications: empirical and theoretical perspectives. In: Zentralblatt für Didaktik der Mathematik 38(2).

Kaiser, G., Schwarz, B. \& Tiedemann, S. (2010). Future Teachers' Professional Knowledge on Modeling. In: Lesh, R., Galbraith, P.L., Haines, C.R. \& Hurford, A. (Eds): Modeling Students' Mathematical Modeling Competencies. ICTMA 13. New York: Springer, 433-444.

Kintsch, W. \& Greeno, J. (1985). Understanding word arithmetic problems. In: Psychological Review 92 (1), 109-129.

Krainer, K. (1993). Powerful tasks: A contribution to a high level of acting and reflecting in mathematics instruction. In: Educational Studies in Mathematics 24, 65-93.

Kramarski, B., Mevarech, Z.R. \& Arami, V. (2002). The effects of metacognitive instruction on solving mathematical authentic tasks. In: Educational Studies in Mathematics 49(2), 225-250.

Kunter, M. \& Voss, T. (2013). The Model of Instructional Quality in COACTIV: A Multicriteria Analysis. In: Kunter, M., Baumert, J., Blum, W. et al. (Eds), Cognitive Activation in the Mathematics Classroom and Professional Competence of Teachers - Results from the COACTIV Project. New York: Springer, 97-124.

Kunter, M., Baumert, J., Blum, W. et al. (Eds, 2013). Cognitive Activation in the Mathematics Classroom and Professional Competence of Teachers - Results from the COACTIV Project. New York: Springer.

Lave, J. (1992). Word problems: a microcosm of theories of learning. In: Light, P. \& Butterworth, G. (Eds). Context and cognition: Ways of learning and knowing. New York: Harvester Wheatsheaf, 74-92.

Leikin, R. \& Levav-Waynberg, A. (2007). Exploring mathematics teacher knowledge to explain the gap between theory-based recommendations and school practice in the use of connecting tasks. In: Educational Studies in Mathematics 66, 349-371.

Leiß, D. (2007). Lehrerinterventionen im selbständigkeitsorientierten Prozess der Lösung einer mathematischen Modellierungsaufgabe. Hildesheim: Franzbecker.

Leiß, D. (2010). Adaptive Lehrerinterventionen beim mathematischen Modellieren - empirische Befunde einer vergleichenden Labor- und Unterrichtsstudie. In: Journal für MathematikDidaktik 31 (2), 197-226.

Lesh, R.A. \& Doerr, H.M. (2003). Beyond constructivism: A models and modelling perspective on teaching, learning, and problem solving in mathematics education. Mahwah: Lawrence Erlbaum.

Lingefjärd, T. (2013). Teaching mathematical modeling in teacher education: Efforts and results. In: Yang, X.-S. (Ed.), Mathematical Modeling with Multidisciplinary Applications. Holboken, Wiley, 57-80.

Maaß, K. (2006). What are modelling competencies? In: Zentralblatt für Didaktik der Mathematik $38(2), 113-142$.

Maaß, K. (2007). Modelling in Class: What do we want the students to learn? In: Haines, C. et al. (Eds), Mathematical Modelling: Education, Engineering and Economics. Chichester: Horwood, 63-78.

Matos, J.F. \& Carreira, S. (1997). The quest for meaning in students' mathematical modelling activity. In: Houston, S.K. et al. (Eds), Teaching \& Learning Mathematical Modelling. Chichester: Horwood, 63-75.

Nesher, P. (1980). The stereotyped nature of school word problems. In: For the Learning of Mathematics 1(1), 41-48.

Neubrand, M. (2006). Multiple Lösungswege für Aufgaben: Bedeutung für Fach, Lernen, Unterricht und Leistungserfassung. In: Blum, W., Drüke-Noe, C., Hartung, R. \& Köller, O. (Eds), Bildungsstandards Mathematik: konkret. Sekundarstufe I: Aufgabenbeispiele, Unterrichtsanregungen, Fortbildungsideen. Berlin: Cornelsen, 162-177.

Niss, M. (1996). Goals of mathematics teaching. In: Bishop, A. et al. (Eds), International Handbook of Mathematical Education. Dordrecht: Kluwer, 11-47.

Niss, M. (1999). Aspects of the nature and state of research in mathematics education. In: Educational Studies in Mathematics 40, 1-24. 
Niss, M. (2003). Mathematical Competencies and the Learning of Mathematics: The Danish KOM Project. In: Gagatsis, A. \& Papastavridis, S. (Eds), 3rd Mediterranean Conference on Mathematical Education. Athens: The Hellenic Mathematical Society, 115-124.

Niss, M. \& Højgaard Jensen, T. (Eds, 2011). Competencies and Mathematical Learning. Roskilde University.

Niss, M., Blum, W. \& Galbraith, P. (2007). Introduction. In: W. Blum et al. (Eds), Modelling and Applications in Mathematics Education. New York: Springer, 3-32.

OECD (2013). PISA 2012 Assessment and Analytical Framework: Mathematics, Reading, Science, Problem Solving and Financial Literacy. Paris: OECD Publishing.

Palm, T. (2007). Features and impact of the authenticity of applied mathematical school tasks. In: Blum, W. et al. (Eds), Modelling and Applications in Mathematics Education. New York: Springer, 201-208.

Pollak, H.O. (1969). How can we teach applications of mathematics? In: Educational Studies in Mathematics 2, 393-404.

Pollak, H. (1979). The Interaction between Mathematics and Other School Subjects. In: UNESCO (Ed.), New Trends in Mathematics Teaching IV. Paris, 232-248.

Reusser, K. (2001). Co-constructivism in educational theory and practice. In: Smelser, N.J., Baltes, P. \& Weinert, F.E. (Eds), International Encyclopedia of the Social and Behavioral Sciences. Oxford: Pergamon/Elsevier Science, 2058-2062.

Reusser \& Stebler (1997). Every word problem has a solution: The suspension of reality and sense-making in the culture of school mathematics. In: Learning and Instruction 7, 309-328.

Rittle-Johnson, B. \& Star, J.R. (2009). Compared With What? The Effects of Different Comparisons on Conceptual Knowledge and Procedural Flexibility for Equation Solving. In: Journal of Educational Psychology 101(3), 529-544.

Schmidt, W.H., Tatto, M.T., Bankov, K., Blömeke, S., Cedillo, T., Cogan, L., et al. (2007). The preparation gap: Teacher education for middle school mathematics in six countries (MT21 Report). East Lansing: MSU Center for Research in Mathematics and Science Education.

Schoenfeld, A.H. (1988). When good teaching leads to bad results: The disasters of "well-taught" mathematics courses. In: Educational Psychologist 23, 145-166.

Schoenfeld, A.H. (1991). On mathematics as sense-making: An informal attack on the unfortunate divorce of formal and informal mathematics. In: Voss, J.F., Perkins, D.N. \& Segal, J.W. (Eds), Informal Reasoning and Education. Hillsdale: Erlbaum, 311-343.

Schoenfeld, A.H. (1992). Learning to think mathematically: problem solving, metacognition, and sense-making in mathematics. In: Grouws, D. (Ed.), Handbook for Research on Mathematics Teaching and Learning. New York: MacMillan, 334-370.

Schoenfeld, A.H. (1994). Mathematical Thinking and Problem Solving. Hillsdale: Erlbaum.

Schukajlow, S. (2011). Mathematisches Modellieren. Schwierigkeiten und Strategien von Lernenden als Bausteine einer lernprozessorientierten Didaktik der neuen Aufgabenkultur. Münster: Waxmann.

Schukajlow, S., Leiss, D., Pekrun, R., Blum, W., Müller, M. \& Messner, R. (2012). Teaching methods for modelling problems and students' task-specific enjoyment, value, interest and selfefficacy expectations. In: Educational Studies in Mathematics 79(2), 215-237.

Schukajlow, S. \& Krug, A. (2013). Considering multiple solutions for modelling problems design and first results from the MultiMa-Project. In: Stillman, G. et al. (Eds), Teaching Mathematical Modelling: Connecting to Teaching and Research Practice - the Impact of Globalisation. New York: Springer,.

Shoaf, M.M., Pollak, H. \& Schneider, J. (2004). Math Trails. Lexington: COMAP.

Smit, J., van Eerde H. A. A. \& Bakker, A. (2013). A conceptualisation of whole-class scaffolding. British Educational Research Journal 39(5), 817-834.

Sol, M., Giménez, J. \& Rosich, N. (2011). Project Modelling Roites in 12- 16-Year-Old Pupils. In: Kaiser, G. et al. (Eds). Trends in Teaching and Learning of Mathematical Modelling (ICTMA 14). Dordrecht: Springer, 231-240. 
Staub, F.C. \& Reusser, K. (1995). The role of presentational structures in understanding and solving mathematical word problems. In: Weaver, C.A., Mannes, S. \& Fletcher, C.R. (Eds), Discourse comprehension. Essays in honor of Walter Kintsch. Hillsdale: Lawrence Erlbaum, 285-305.

Stillman, G. (2011). Applying Metacognitive Knowledge and Strategies in Applications and Modelling Tasks at Secondary School. In: Kaiser, G. et al. (Eds). Trends in Teaching and Learning of Mathematical Modelling (ICTMA 14). Dordrecht: Springer, 165-180.

Stillman, G. \& Galbraith, P. (1998). Applying mathematics with real world connections: Metacognitive characteristic of secondary students. In: Educational Studies in Mathematics 36 (2), 157-195.

Stillman, G., Kaiser, G., Blum, W. \& Brown, J. (Eds, 2013). Teaching Mathematical Modelling: Connecting to Teaching and Research Practice - the Impact of Globalisation. New York: Springer.

Timperley, H.S. (2011). Realizing the Power of Professional Learning. London: Open University Press.

Treilibs, V., Burkhardt, H. \& Low, B. (1980). Formulation processes in mathematical modelling. Nottingham: Shell Centre for Mathematical Education.

Tsamir, P., Tirosh, D., Tabach, M. \& Levenson, E. (2010). Multiple solution methods and multiple outcomes - is it a task for kindergarten children? In: Educational Studies in Mathematics 73, 217-231.

Turner, R., Dossey, J., Blum, W. \& Niss, M. (2013). Using Mathematical Competencies to Predict Item Difficulty in PISA: A MEG Study. In: Prenzel, M., Kobarg, M., Schöps, K. \& Rönnebeck, S. (Eds.), Research on PISA - Research Outcomes of the PISA Research Conference 2009. New York: Springer, 23-37.

Verschaffel, L., Greer, B. \& DeCorte, E. (2000). Making Sense of Word Problems. Lisse: Swets \& Zeitlinger.

Verschaffel, L., van Dooren, W., Greer, B. \& Mukhopadhyay, S. (2010). Reconceptualising Word Problems as Exercises in Mathematical Modelling. In: Journal für Mathematik-Didaktik 31(1), 9-29.

Vos, P. (2007). Assessment of applied mathematics and modelling: Using a laboratory-like environment. In: Blum, W. et al. (Eds), Modelling and Applications in Mathematics Education. New York: Springer, 441-448.

Xin, Z., Lin, C., Zhang, L. \& Yan, R. (2007). The performance of Chinese primary school students on realistic arithmetic word problems. In: Educational Psychology in Practice 23, 145-159.

Zöttl, L., Ufer, S. \& Reiss, K. (2011). Assessing modelling competencies using a multidimensional IRT approach. In: Kaiser, G. et al. (Eds), Trends in Teaching and Learning of Mathematical Modelling (ICTMA 14). Dordrecht: Springer, 427-437. 